\title{
The properties of retrieval cues constrain the picture superiority effect
}

\author{
MARY SUSAN WELDON, HENRY L. ROEDIGER III, and BRADFORD H. CHALLIS \\ Purdue University, West Lafayette, Indiana
}

In three experiments, we examined why pictures are remembered better than words on explicit memory tests like recall and recognition, whereas words produce more priming than pictures on some implicit tests, such as word-fragment and word-stem completion (e.g., completing 1 _ ph_nt or ele___ as elephant). One possibility is that pictures are always more accessible than words if subjects are given explicit retrieval instructions. An alternative possibility is that the properties of the retrieval cues themselves constrain the retrieval processes engaged; word fragments might induce data-driven (perceptually based) retrieval, which favors words regardless of the retrieval instructions. Experiment 1 demonstrated that words were remembered better than pictures on both the word-fragment and word-stem completion tasks under both implicit and explicit retrieval conditions. In Experiment 2, pictures were recalled better than words with semantically related extralist cues. In Experiment 3, when semantic cues were combined with word fragments, pictures and words were recalled equally well under explicit retrieval conditions, but words were superior to pictures under implicit instructions. Thus, the inherently datalimited properties of fragmented words limit their use in accessing conceptual codes. Overall, the results indicate that retrieval operations are largely determined by properties of the retrieval cues under both implicit and explicit retrieval conditions.

Generally, people remember pictures better than words (e.g., Paivio, 1971; Paivio, Rogers, \& Smythe, 1968; Shepard, 1967). Although the basis of the picture superiority effect is not entirely clear, several aspects of encoding have been identified as causal. For example, the dual coding hypothesis (Paivio, 1971, 1983, 1986) posits that under ordinary circumstances, pictures are likely to become redundantly encoded because they evoke both imaginal and verbal codes, whereas words are likely to evoke only verbal codes. The sensory-semantic model (Nelson, 1979) implicates the role of stimulus surface features: pictures provide more distinctive visual representations than do words, and hence they are more memorable. Other researchers (Intraub \& Nicklos, 1985; Nelson, Reed, \& McEvoy, 1977; Smith \& Magee, 1980) have suggested that pictures naturally engage deeper "levels of processing" (Craik \& Lockhart, 1972) than do words. Experimental evidence includes the findings that pictures can be categorized faster than words (Potter \& Faulconer, 1975; Smith \& Magee, 1980), and that words processed semantically or elaboratively are remembered as well as pictures (Durso \& Johnson, 1980). Despite the differences in the specific mechanisms postulated in the various theories of the picture superiority effect, all the theories share

Preparation of this article was supported in part by Grant HD15054 07 from the National Institute of Child Health and Human Development. We thank Douglas Nelson for helpful comments on an earlier draft. The second author is now at Rice University, Houston, TX. Requests for reprints should be sent to Mary Susan Weldon, who is now at the Program in Experimental Psychology, Kerr Hall, University of California, Santa Cruz, CA 95064. the notion that, in one way or another, pictures produce more elaborated codes than words do.

In a recent series of experiments, Weldon and Roediger (1987; Roediger \& Weldon, 1987) have demonstrated that not only are encoding factors important in the picture superiority effect, but retrieval processes are critical as well. They hypothesized that pictures are more memorable than words not simply because they engage more elaborative encoding processes, but because the memory tests that typically are used to measure the effect are particularly sensitive to elaborative processing. For example, a typical memory test involving recall or recognition requires deliberate recollection of a prior experience, and it is well known that performance on such tests is enhanced by semantic encoding tasks (e.g., Craik \& Tulving, 1975). If picture processing provides greater representation of semantic features than the processing of words does, then traditional memory tests might favor picture retrieval simply because they enable the subject to make use of the semantic information. It follows, then, that a memory test that does not rely on such conceptual information should not show a benefit of deeper levels of processing, and that it thus might not show a picture superiority effect. Specifically, words should be remembered better than pictures in a retrieval task that is primarily sensitive to the perceptual processing of the surface features of words.

In order to test this hypothesis, Weldon and Roediger (1987) presented mixed lists of pictures and words to subjects; half the subjects then received a free recall test, and the other half received a word-fragment completion task (Tulving, Schacter, \& Stark, 1982), in which they tried 
to form complete words by supplying the letters missing from fragmented words such as $\mathrm{l}_{-} \mathrm{p}_{-} \mathrm{a}_{-} \mathrm{t}$ for elephant. Some of the word fragments were made from the words and names of the pictures presented earlier, although the subjects were not told this. The measure of interest in this task was priming, or the increased probability of completing a fragment that referred back to a previously studied item as compared to a nonstudied item.

As was expected on the free recall test, pictures were remembered better than words. On the fragment completion task, however, words produced significantly more priming than pictures (cf. Warren \& Morton, 1982; Winnick \& Daniel, 1970). Thus, the picture superiority effect was reversed by changing only the type of retrieval task, suggesting that picture superiority is not just a function of differential encoding of pictures and words, but of retrieval demands as well.

Weldon and Roediger (1987) interpreted this dissociation by suggesting that the word-fragment completion test is data-driven (see Jacoby, 1983), meaning that it taps memory for perceptual processing. As such, priming in this task depends on the degree to which the perceptual operations performed at test match those performed during study. Because the surface features of the studied words are similar to those of the test fragments, the perceptual analyses of both types of stimuli are similar. That is, the processes involved in reading words provide a good match with the processes involved in decoding word fragments. On the other hand, the surface features of pictures are very dissimilar to those of word fragments, and so pictures produce very little priming.

In contrast to the data-driven nature of the wordfragment completion test, free recall is considered to be conceptually driven. Performance on conceptually driven tests benefits when targets are semantically elaborated during encoding, because distinctive and relational information form the basis of retrieval on such tests. Thus, for example, pictures produce better recall than words because pictures engage more elaborative encoding processes. (See Roediger \& Blaxton, 1987, and Roediger, Weldon, \& Challis, 1989, for a review of the evidence supporting this theoretical framework.)

The purpose of the experiments reported here was to investigate further the nature of the processes that produce dissociations between free recall and word-fragment completion as a function of the symbolic format of the studied material (pictures vs. words). We have argued that on a conceptually driven task such as free recall, pictures are remembered better than words because they produce more elaborated codes. But exactly how does this encoding help free recall? One possibility is that elaborative encoding supports the strategies used to search memory during explicit retrieval tests (i.e., those that require conscious recollection; see Graf \& Mandler, 1984), such as free recall. For example, elaborative encoding might establish more retrieval routes, or might improve the discriminability of the item (Eysenck, 1979).

Why would elaborative encoding fail to help performance on the word-fragment completion test? Word- fragment completion is an implicit memory test, so it requires neither conscious recollection of the studied items nor awareness of the relation between the study and test items. Because implicit tasks can be performed without reference to specific prior episodes, factors that help explicit retrieval, such as deeper levels of processing, might not confer similar benefits on implicit retrieval. However, if pictures improve recall because they facilitate explicit search strategies, then if subjects are instructed to use word fragments as recall cues (i.e., are given explicit retrieval instructions), the picture superiority effect should be reinstated on the word-fragment completion test.

An alternative hypothesis is that under explicit retrieval instructions, performance on the word-fragment completion test would not be controlled by search strategies, but would be determined by the properties of the retrieval cues themselves. Note that word fragments (e.g., $\left.-y \_a \_i \_\right)$provide perceptually degraded information, which the subject must resolve into an integrated, meaningful lexical unit. The properties of the stimuli might trigger a search for words with similar orthographic properties (e.g., ___ words with an $o$ and $e$ in the fourth and fifth positions). In this scenario, semantic encoding would not necessarily facilitate retrieval because it elaborates information irrelevant to the retrieval demands. In sum, the retrieval processes that underlie word-fragment completion might be driven by the demand for perceptual resolution of the test cues. If so, then pictures will not be recalled better than words on a word-fragment completion test, even under explicit retrieval instructions. Neither the physical nor the semantic properties of pictures will be helpful in providing the orthographic information required to solve the fragments (pyramid and canoe in the examples above).

To summarize, the purpose of the experiments reported here was to examine the role of retrieval processes in the picture superiority effect. Prior research has shown that words produce more priming than pictures on an implicit word-fragment completion task. One possible explanation of this outcome is that implicit tests do not involve deliberate memory search, and so they do not make use of the information provided by the elaborated encodings produced when pictures are studied. If this explanation is correct, then the picture superiority effect should reemerge on the word-fragment completion task under explicit retrieval instructions. However, an alternative possibility is that the retrieval orientation is irrelevant, and that the properties of the retrieval cues themselves control the interaction between study format (pictures vs. words) and test type (recall vs. word-fragment completion). In order to test between these two possibilities, we conducted three experiments, varying the retrieval orientation (implicit vs. explicit) and the properties of the retrieval cues presented during testing.

\section{EXPERIMENT 1}

The purpose of Experiment 1 was to determine whether the picture superiority effect would be obtained on the 
word-fragment completion test under explicit retrieval instructions. The subjects studied mixed lists of pictures and words, then received either a word-fragment (e.g., ___p_a_t) or a word-stem completion (e.g., ele___ test, on which some of the fragments or stems referred to the words and names of the pictures studied earlier. Half the subjects in each test group received the usual implicit test instructions to complete the fragments or stems with the first word that came to mind; they were not told that some were the items on the slides. The other half of the subjects in each group received explicit retrieval instructions: they were told to use each fragment as a retrieval cue to help them remember the words and pictures they had studied earlier. A fifth group received only a free recall test.

The comparison of the fragment and stem completion tasks is interesting for several reasons. First, some researchers have argued that the stem completion task is a more appropriate measure of priming than the fragment completion task (e.g., Graf \& Mandler, 1984; Squire, Shimamura, \& Graf, 1987). Word stems typically have many possible solutions, and subjects can complete the stems easily and quickly. In contrast, word fragments have unique solutions, are quite difficult to complete (baseline performance typically ranges from $20 \%-35 \%$ ), and are completed more slowly and effortfully than stems. Because the task is so difficult, its critics have suggested that once subjects notice that some of the fragments come from the previously studied items, they may use explicit retrieval strategies to help solve them. Furthermore, the fragment completion task involves a considerable degree of problem-solving, which may cloud its use as a measure either of "automatic accessibility" (Graf \& Mandler, 1984) or of the increased availability of the previously studied items.

Despite these differences, the results of several pilot experiments led us to believe that word-fragment and word-stem completion both tap similar (data-driven) aspects of memory when used for implicit memory tests. However, the two tests have never been directly compared in the same experiment, using identical materials and instructions. We predicted that they would exhibit similar patterns of effects, providing evidence that they involve similar retrieval processes.

\section{Method}

Subjects and Design. The subjects were 150 Purdue undergraduates, who participated for credit in introductory psychology. All were native English speakers and had normal or corrected vision.

Study format (pictures, words, nonstudied) was manipulated within-subjects, and test type was manipulated between subjects, with 30 subjects participating in each of the following test groups: implicit word-fragment completion, implicit word-stem completion, explicit word-fragment completion, explicit word-stem completion, and free recall. The items were completely counterbalanced across tests, subjects, and study formats as described below.
Materials. Thirty-nine target items and 10 buffer items were selected from the Snodgrass and Vanderwart (1980) picture set and from our own pool of items. Two slides were obtained for each target item, one containing a black-and-white line drawing, and the other the name of the item typed in lower case letters. The items were selected to meet several criteria. First, the drawings showed high label agreement $(95 \%)$ when a separate group of 50 subjects was asked to provide a name for each drawing. Second, each item had a word-fragment frame with a unique solution (e.g., s_ui_ re_ for squirrel). The average baseline (nonstudied) completion rate for the fragments was $35 \%$ when they were tested on separate groups of subjects. Each target item also had a word stem with at least six alternative completions in Webster's Unabridged Dictionary (2nd. ed.), and no target, buffer, or filler item shared the same first three letters with any other.

The 39 target items were divided into three sets, which were rotated through the picture, word, and nonstudied conditions so that each target item was assigned to each study format an equal number of times across subjects in all five test groups. The pictures and words were randomly mixed on the study lists, with the constraint that no more than three pictures or words appeared sequentially. Four buffer items were placed at the beginning and end of the study list.

The fragment completion test contained all 39 target words and one filler item that was not scored. The fragments were typed in random order, with 20 items per page. The test pages were collated so that the first page on half the tests was the second page on the other tests, and the booklets were randomly distributed during testing. The stem completion test was structured like the fragment test, except that the first three letters of the words (e.g., ele

Two distractor tasks were prepared. One contained a list of fragments or stems for 20 famous names (e.g., C_pe_ni_us or Cop__ for Copernicus), and the second contained a list of fragments or stems for $\mathbf{2 0}$ common nouns that were not among the target or buffer items. The subjects in the fragment completion test groups received the fragment filler tasks, and those in the stem completion groups received the stem filler task. In the free recall group, half the subjects received the wordfragment and half received the word-stem versions of the filler tasks.

Procedure. The subjects were tested in groups of 2 to 5 . They were told that they would study slides of pictures and words, and that they would receive a memory test after they had performed some other tasks; but they were not told the nature of the memory test. The slides were presented for $5 \mathrm{sec}$ each.

The subjects were then told that they were going to perform a few tasks that would help us prepare materials for future research projects. First, they were given $10 \mathrm{~min}$ to write the states and state capitals. Next, they were given the famous-name completion task, and they were instructed to complete the fragments or stems with the last names of famous people. They were told that they would have $15 \mathrm{sec}$ to solve each item, and that at the end of each interval they should move to the next item. The experimenter timed the intervals. The subjects used a cover sheet to conceal the upcoming fragments, and they were instructed not to work ahead or to return to any items. Finally, the subjects performed the common-noun completion task. The instructions were the same, but they were told to complete the fragments or stems with one-word common nouns.

The subjects then received the appropriate retrieval test. In the implicit fragment and implicit stem completion groups, the 
subjects were given the same instructions they had received for the filler tasks, and they were not given any indication that the solutions of many of the items were the words and names of pictures they had studied on the slides.

The subjects in the explicit retrieval groups were told that they were receiving the memory test for the slides. They were told that they would receive retrieval cues in the form of fragments or stems made from the words and the names of the pictures they had studied, and that they should use these fragments as clues to help them remember the items. They were also told that some of the fragments or stems were not items they had studied, and that they should not complete these, even if they could think of a solution. They were instructed to be reasonably sure that their completions were studied items.

For both the implicit and explicit tests, the subjects were given $15 \mathrm{sec}$ to solve each item; they used a cover sheet to cover all upcoming items, and they were told not to work ahead nor to return to any items. After finishing the tests, the subjects in all four groups were asked to go back over the completed items and rate each on a 6-point scale, with respect to how certain they were that it referred to either a picture or a word they had studied earlier. A rating of " 1 " indicated they were very sure they had not studied it, and a "6," that they were very sure they had studied it.

The subjects in the free recall test group were given $7 \mathrm{~min}$ to recall as many of the previously studied pictures and words as possible.

\section{Results}

Group means are presented as proportions correct in Table 1. For the implicit instructions groups, both total proportions correct and priming (studied - nonstudied) proportions are presented. For the explicit groups, both total and adjusted (studied - false alarms) proportions are presented. For all significant effects reported in the following experiments, $p<.05$.

Implicit word-fragment and word-stem completion. A $2 \times 2$ mixed ANOVA compared priming for pictures and words on the word-stem and word-fragment completion tests. Priming scores were computed by subtracting each subject's nonstudied baseline completion rate from the total completion rates for pictures and for words. The priming score is more interpretable than the total proportions correct, because the baseline rates differ between fragment completion and stem completion. Because the stems had many completions possible, whereas the fragments had only one, baseline rates for target completions were lower on the stem completion task. This difference in baseline performance levels is not interesting in the present context, because we are asking whether the two tests show similar patterns of effects, not similar levels of performance. Of course, subtracting baselines does not solve the scaling problems inherent in comparisons of different measures.

The ANOVA revealed a significant main effect of study format. As predicted, words $(M=0.14)$ produced more priming than pictures $[M=0.05 ; F(1,58)=18.70$, $M S e=0.02]$. These results replicated our previous findings for the word-fragment completion test (Weldon \& Roediger, 1987), and demonstrated that a similar rever-
Table 1

Total Proportions Correct and Priming Proportions in Experiment 1 Study Format

\begin{tabular}{cccc} 
& \multicolumn{3}{c}{ Study Format } \\
\cline { 2 - 3 } Retrieval Instructions & Pictures & Words & $\begin{array}{c}\text { Nonstudied } \\
\text { Baseline }\end{array}$ \\
\hline
\end{tabular}

Implicit Completion Tests

Total

$\begin{array}{llll}\text { Fragment completion } & .40 & .52 & .36\end{array}$

$\begin{array}{llll}\text { Stem completion } & .13 & .19 & .08\end{array}$

Priming

$\begin{array}{llll}\text { Fragment completion } & .04 & .16 & - \\ \text { Stem completion } & .05 & .11 & -\end{array}$

Explicit Cued Recall

Total

Fragment completion $\quad .43 \quad .51$

$\begin{array}{llll}\text { Stem completion } & .38 & .41 & (.06)\end{array}$

Adjusted

$\begin{array}{llll}\text { Fragment completion } & .31 & .39 & -\end{array}$

Stem completion $\quad .32 \quad .35$

Free Recall

.26

.15

Note-priming $=$ studied - nonstudied; adjusted $=$ studied - false alarms; values in parentheses = proportion of false alarms (i.e., target responses provided for nonstudied items).

sal of the picture superiority effect occurred on the wordstem completion task. Neither the main effect of test type $[F(1,58)<1]$, nor the interaction between test type and study format $[F(1,58)=2.08, M S e=0.02, p>.15]$, was significant, indicating that the two tests showed similar patterns of priming, as predicted.

Although we have chosen to report analyses of priming scores, we did perform a 3 (pictures, words, nonstudied) $\times 2$ (fragments vs. stems) ANOVA on total proportions correct. The only results that differed from the analysis of the priming scores was a main effect of test type $[F(1,58)=116.74, M S e=0.03]$, reflecting the difference in baseline levels of performance. A planned comparison revealed that pictures produced significant priming $[F(1,59)=5.42, M S e=0.01]$.

Explicit cued recall with word fragments and stems. A $2 \times 2$ mixed ANOVA was performed on the total proportion of pictures and words correctly recalled, with study format as a within-subjects factor and test type as a between-subjects factor.

The effect of study format, which was the manipulation of primary interest, was significant $[F(1,58)=5.50$, $M S e=0.02]$. Words $(M=0.46)$ were recalled better than pictures $(M=0.40)$, as was observed under implicit test instructions. Thus, the picture superiority effect was not reinstated on the word-fragment and stem-completion tests under explicit retrieval conditions.

The main effect of test type was significant $[F(1,58)$ $=5.47, M S e=0.03]$, such that more items were recalled on the fragment completion test $(M=0.47)$ than on the stem completion test $(M=0.39)$. However, the interaction between test type and study format was not significant $[F(1,58)=1.20, M S \mathrm{e}=0.02, p>.25]$, again indicating that the two tests provided similar measures of retention. 
The subjects completed a certain number of nonstudied items with targets, even though they were instructed to complete only those items that they were relatively confident of having studied previously. These false alarm rates were $12 \%$ in the fragment completion group and $6 \%$ in the stem completion group. The difference was just significant $[F(1,58)=4.09, M S e=0.01, p=.05]$. The appropriate correction for false alarms is unclear, but an ANOVA was performed on adjusted hit rates, computed by subtracting false alarms from the total proportions correct. This correction eliminated the main effect of test type, but did not change the main conclusion that words were remembered better than pictures on both tests.

Taken together, the analyses of the implicit and explicit test conditions indicate that words produced better performance than pictures, regardless of the retrieval instructions, and this same pattern of results was obtained on both the word-fragment and word-stem completion tests. A $2 \times 2 \times 2$ mixed-factor ANOVA, performed with test type (word-fragment vs. word-stem completion) and test orientation (implicit vs. explicit instructions) evaluated between subjects, and item format (pictures vs. words) evaluated within subjects, led to the same conclusion. The three-way interaction between test type, study format, and retrieval orientation was not significant $[F(1,116)<1]$.

Free recall. As expected, pictures $(M=0.26)$ were recalled better than words $[M=0.15 ; t(29)=3.27$, $S E=0.03$ ]. This condition was included to verify that the picture superiority effect would be obtained on a standard free recall test with the materials used here, but it is not of primary interest and will not be discussed further.

Confidence ratings. Confidence ratings for pictures, words, and nonstudied items that were completed with target items on the fragment and stem tests are displayed for the implicit and explicit instructions groups in Table 2.

For the implicit test groups, these confidence ratings are interesting because they serve as a recognition test for the items completed under implicit retrieval instructions, so we can look for a dissociation between the priming and recognition measures as a function of study format. A mixed two-way ANOVA performed on the ratings in the implicit instructions groups revealed that pictures $(M=4.7)$ were recognized more confidently than words $[M=4.2 ; F(1,58)=3.47, M S e=2.37]$, which was marginally significant $(.05<p<.10)$. Thus, even

Table 2

Recognition Confidence Ratings for Target Completions in Experiment 1

\begin{tabular}{llll}
\hline & \multicolumn{2}{c}{ Study Format } \\
\cline { 2 - 3 } Retrieval Instructions & Pictures & Words Nonstudied \\
\hline
\end{tabular}

Implicit Completion Tests

$\begin{array}{lccc} & & \\ \text { Fragment completion } & 5.6 & 5.2 & 2.1 \\ \text { Stem completion } & 3.9 & 3.2 & 1.2\end{array}$

Explicit Cued Recall

$\begin{array}{llll}\text { Fragment completion } & 5.7 & 5.1 & 2.0\end{array}$

Stem completion $\quad 5.9 \quad 5.7 \quad 5.1 .3$ though words had produced substantially more priming than pictures on the word-completion tasks performed immediately before the recognition test, the items that had been studied as pictures were recognized more confidently.

Similar results were obtained in the explicit cued recall groups. Again, even though words were retrieved more successfully on the cued recall tests, pictures $(M=5.8)$ were recognized more confidently than words $(M=5.4)$ during the recognition phase. A two-way mixed ANOVA revealed the difference to be significant $[F(1,58)=5.63$, $M S \mathrm{e}=0.81]$. The ceiling effect suggests that the subjects followed instructions and did not complete the stems or fragments unless they were quite certain they had studied the item earlier.

These findings provide evidence for a dissociation between the completion tasks and the recognition task. Even though more words than pictures were retrieved in the completion tasks, the picture superiority effect was obtained during the recognition phase on the exact same test items. (See Madigan, 1983, who also obtained a picture superiority effect on a word recognition test.)

\section{Discussion}

The important results that emerged from this experiment are the following: (1) explicit retrieval instructions were not sufficient to produce the picture superiority effect when word fragments and word stems were used as retrieval cues; and (2) word fragment and stem completion represent similar measures of memory with either implicit or explicit test instructions, at least under the conditions examined here.

Why did the picture superiority effect fail to materialize when the word fragments and word stems were used as explicit retrieval cues? We suggest that explicit retrieval processes were constrained by the properties of the test cues themselves. That is, performance is not simply a function of the retrieval strategies that subjects are instructed to employ (i.e., implicit vs. explicit); the properties of the retrieval cues themselves limit the effectiveness of different retrieval strategies. Specifically, good retrieval depends on the degree to which the cognitive processes required to use the cues recapitulate specific processes engaged during study. Cues in the form of word fragments or stems are perceptually degraded or "datalimited" stimuli, such that successful solution depends more upon appropriate perceptual than conceptual processes. Relative to encoding a picture, the cognitive operations involved in reading a word overlap more with the operations required to solve a word fragment, and thus produce greater transfer. Fragmentary test stimuli may be inherently data-driven because of their data-limited properties, and this may constrain retrieval processes in a way that cannot be overcome simply by using explicit retrieval strategies.

Nelson and his colleagues (Nelson, Canas, Bajo, \& Keelean, 1987; Nelson, in press) have expressed similar ideas by distinguishing among different types of memory 
searches, particularly "lexical search" and "conceptual search." Nelson proposes that in cued recall, the properties of the test cues determine the properties of the set of items in memory that will be searched. For example, phonemic cues activate sets of words that rhyme, word fragments activate sets of words that share common letters, and semantic cues activate sets of conceptually related items. The activated sets are then searched for an acceptable response. Nelson et al. (1987, Experiment 4) demonstrated that the set of related information that is activated by a retrieval cue depends on the nature of the retrieval cues themselves, and not on whether the subjects receive implicit or explicit retrieval instructions. These findings are consistent with our suggestion that the properties of the test cues determine the basis of retrieval.

If our interpretation is correct, then we should be able to obtain a picture superiority effect on a cued recall test by using semantically related test cues. Experiment 2 was conducted to test this hypothesis.

\section{EXPERIMENT 2}

The results of Experiment 1 led us to suggest that cue properties largely determine the nature of retrieval processes. We found that changing retrieval instructions to encourage explicit memory search on the fragment and stem completion tasks did not engender conceptually based retrieval processes, presumably because the fragmented stimuli are inherently data-limited. However, if the datadriven component is removed and replaced by retrieval cues that are semantically related to the study items, then pictures should be remembered better than words. That is, semantically related extralist cues should engage retrieval processes based on encoded meaning, and the picture superiority effect should obtain. A review of the paired-associate learning and cued recall literature failed to uncover a test of this hypothesis, so we performed the following experiment. We attempted to conduct the experiment as similarly as possible to Experiment 1, in order to permit meaningful cross-experiment comparisons.

\section{Method}

Subjects and Design. The subjects were 40 Purdue undergraduates who participated for course credit. All were native English speakers who had not participated in Experiment 1. Study format (pictures vs. words) was manipulated within subjects, and the items were appropriately counterbalanced across subjects.

Materials. Sixty common concrete target items were selected as in Experiment 1; they included the 39 items used in Experiment 1. For each target item, a strong associate was selected as an extralist recall cue (e.g., tusk as a cue for elephant). An attempt was made to minimize similarities among list items and the cues associated with each item, so that each response was likely to be paired with only one cue. Baseline norms collected from a separate group of 24 subjects indicated that $19 \%$ of the target items were generated when subjects were asked to write down the first thing that came to mind when they read the cue word alone.

The items were randomly divided into two sets. One set was presented as pictures and the other as words, to half the subjects; the remaining subjects saw the items in the opposite formats. As in Experiment 1, the items were randomly assigned to list positions, with the restriction that no more than three pictures or words appear sequentially. Four pictures and words that were unrelated to the list items and cues appeared at the beginning and end of each list, as buffer items.

The cued recall test sheet consisted of three pages, each containing 20 cues in random order. The pages were collated in all possible orders equally often, and the booklets were randomly distributed during testing.

Procedure. The items were presented in the same manner as in Experiment 1. After studying the slides, the subjects received their cued recall test books. This test was administered in a manner similar to that for the explicit fragment and stem completion tests in Experiments 1 and 2 . The subjects were told that the cue words were meaningfully related to the pictures and words that they had studied, and they were given an example. The subjects were told to use the cues to help them recall the items, and to write each recalled item next to the cue; but they were told not to guess wildly. They were given $15 \mathrm{sec}$ to recall each item; they used a cover sheet to hide upcoming items, and they were told not to work ahead or to go back to any items.

\section{Results and Discussion}

The subjects' responses were scored with a strict criterion: only studied items given as responses to the intended cues were counted as correct. (Scoring by a lenient criterion in which the recall of any studied item was counted as correct, regardless of whether it was recalled to the intended or to some other cue, did not change the pattern of results.) Cued recall was significantly higher for pictures $(M=0.72)$ than words $[M=0.56 ; t(39)=7.64$, $S E=0.02]$. Thus, as predicted, the picture superiority effect was obtained in cued recall with conceptually related extralist cues.

This result supports our argument that properties of the retrieval cues can determine the basis of retrieval. Cued recall with associatively related items is conceptually driven, because it requires the use of information about an item's meaning and its semantic relation to another item. Because pictures induce more conceptual processing, pictures were easier to retrieve than words on this type of cued recall test. These results also rule out the possibility that the failure to find a picture superiority effect with word-fragment and word-stem cues in Experiment 1 was due to a general absence of picture superiority effects in cued recall.

\section{EXPERIMENT 3}

We have demonstrated that the picture superiority effect is largely determined by the properties of the retrieval cues. In Experiment 1, words produced more priming than pictures in two data-driven tasks, the word-fragment and word-stem completion tests. In these tasks, the retrieval cues were data-limited, so successful retrieval depended on the subjects' having performed appropriate perceptual operations during the study phase. In Experiment 2 , pictures were remembered better than words on a conceptually driven cued recall test. Because the 
retrieval cues were semantically related to the targets, their usefulness depended on the subjects' having performed appropriate conceptual processing during the study phase.

The results of Experiment 1 suggest that the wordfragment completion test is data-driven, regardless of the subjects' retrieval orientation. Yet, if retrieval tasks can be ordered on a continuum representing the degree to which conceptually and data-driven processes are involved, then, in theory, it should be possible to modify the word-fragment completion task to push it toward the conceptually driven end of the continuum. Perhaps explicit retrieval instructions do not provide a manipulation sufficiently strong to engender conceptually based retrieval processes. However, adding conceptual cues to the fragments should add a conceptual component to the retrieval task. If so, the picture superiority effect should emerge. Thus, in Experiment 3, we tested this hypothesis by combining conceptually based retrieval cues (semantic associates) with data-driven retrieval cues (word fragments).

\section{Method}

Subjects and Design. One hundred and eighty Purdue students participated for credit in introductory psychology. All the subjects were native English speakers who had not participated in the preceding experiments.

All the subjects first studied a mixed list of pictures and words; then they were assigned to one of six test conditions: (1) implicit orientation with fragments only (e.g., $\_$L $\quad P \_$A $\_$T); (2) implicit orientation with semantically cued fragments (e.g., trunk L P_A _ T); (3) explicit retrieval with fragments only; (4) explicit retrieval with semantically cued fragments; (5) semantic cued recall (e.g., trunk ___ _); and (6) free recall. The items were completely counterbalanced across study and test conditions.

Materials. Ninety target items were selected from the same pool of items used in Experiments 1 and 2. Words were typed in uppercase letters on the word slides; the picture slides were the same ones that were used in the previous experiments. A weak semantic associate was selected for each item such that when the semantically related cue was presented alongside the corresponding fragment (e.g., plane _ AR_CH_T__ ), the average nonstudied completion rate for the fragments was approximately $50 \%$ (when tested on a separate group of $\mathbf{5 0}$ subjects).

The 90 target items were divided into three sets that were rotated through the picture, word, and nonstudied conditions. Pictures and words were randomly mixed in the study lists, with the provision that no more than four words or pictures appear in sequence.

The test cues were randomly ordered on the test forms. In the fragment only condition, only the fragments were presented. In the cued fragment condition, the semantically related word was presented alongside the corresponding fragment typed in uppercase letters (e.g., plane _ AR_CH_T__). For the semantic cued recall test, only the semantic cue was presented (e.g., plane

Procedure. The subjects were tested in groups of 10 to 12 . At study, they were instructed to observe slides of pictures and words, with no mention of a later memory test. The slides were presented for $5 \mathrm{sec}$ each. Following the study session, the subjects spent $5 \mathrm{~min}$ writing the names of states and state capitals.

The test instructions for the word-fragment completion tests were similar to those administered in Experiment 1. Subjects were given $12 \mathrm{sec}$ to complete each fragment. In the implicit fragment completion groups, the subjects were told to complete as many of the fragments as possible. In the implicit cued fragment condition, the subjects were informed that the word next to the fragment might be related to the fragmented word and that it might help them solve it.

In the explicit fragment completion groups, the subjects were instructed to use the fragments as retrieval cues. In the explicit cued fragment condition, the subjects were told that the word alongside the fragment might be related to the fragmented word, and that they should use the cue word and the word fragment to help them remember a picture or word presented earlier. The subjects were told that if they were able to solve the fragment but did not remember seeing either a picture or word of the solution, then they should leave the fragment blank. They were told to be reasonably sure that they saw a picture or word of each fragment before they completed the fragment. After the test, the subjects were asked to look at each fragment they had solved and determine whether they had studied it earlier. A 6-point confidence scale was used, with "6" indicating that they were absolutely certain they had studied the item, and a " 1 " indicating that they were absolutely certain they had not.

In the semantic cued recall test, the subjects were informed that some of the words on the test sheet might help them remember the words and pictures presented earlier. The subjects were given $12 \mathrm{sec}$ per cue to recall a studied item. The subjects in the free recall group were allowed 10 min to recall the words and pictures.

\section{Results and Discussion}

The proportion of word fragments correctly completed for each study $\times$ test condition is presented in Table 3 . Total proportions correct are presented for all test conditions, priming scores (studied - nonstudied) are included for the implicit fragment completion groups, and adjusted scores (studied - false alarms) are presented for the explicit fragment completion groups.

Implicit word fragment completion. A $2 \times 2$ mixed ANOVA was performed on the priming scores, with study format (pictures vs. words) as a within-subjects factor and test cue (fragment only vs. cued fragment) as a between-

Table 3

Total Proportions Correct and Priming Proportions in Experiment 3

\begin{tabular}{lccc}
\hline & \multicolumn{3}{c}{ Study Format } \\
\cline { 2 - 4 } Retrieval Conditions & Pictures & Words & $\begin{array}{c}\text { Nonstudied } \\
\text { Baseline }\end{array}$ \\
\hline \multicolumn{2}{c}{ Implicit } & Fragment & Completion \\
Total & & & \\
$\quad$ Fragment only & .39 & .50 & .30 \\
$\quad$ Cued fragment & .58 & .68 & .52 \\
Priming & & & \\
$\quad$ Fragment only & .09 & .20 & - \\
Cued fragment & .06 & .16 & - \\
& & & \\
Total & Explicit Cued Recall & \\
$\quad$ Fragment only & .37 & .45 & $(.11)$ \\
Cued fragment & .61 & .57 & $(.22)$ \\
Adjusted & & & \\
Fragment only & .26 & .34 & - \\
Cued fragment & .39 & .35 & - \\
Semantic Cued Recall & .51 & .25 & - \\
Free Recall & .35 & .21 & - \\
\hline
\end{tabular}

Note - priming $=$ studied - nonstudied; adjusted $=$ studied - false alarms; values in parentheses = proportion of false alarms (i.e., target responses provided for nonstudied items). 
subjects factor. The main effect of study format was significant $[F(1,58)=45.40, M S e=0.01]$, such that words $(M=0.18)$ produced more priming than pictures $(M=0.08)$, as was observed under implicit test conditions in Experiment 1. Neither the main effect of test cue nor the interaction between test cue and study format was significant $(F \mathrm{~s}<1)$.

A $2 \times 3$ (pictures, words, nonstudied) mixed ANOVA was performed on the total proportions correct, which revealed the same main effect of study format, with no interaction between the study format and test cue. There was a significant effect of test cue $[F(1,58)=35.56$, $M S e=0.05$ ], due to the different performance baselines. Planned comparisons revealed that pictures produced significant priming $[F(1,59)=16.70, M S e=0.01]$.

In sum, the results indicate that under implicit test instructions, the presence of semantic cues in conjunction with word fragments failed to reinstate the picture superiority effect. In fact, the presence of semantic cues even failed to increase the amount of priming observed for pictures and words.

Explicit word fragment completion. A 2 (test cue) $\times$ 2 (pictures vs. words) mixed ANOVA on the proportion of fragments correctly completed revealed a significant main effect of test cue $[F(1,58)=27.64, M S e=0.04]$, no effect of study format $[F(1,58)<1]$, and a significant interaction between test cue and study format $[F(1,58)$ $=7.84, M S e=0.01]$.

Planned comparisons indicated that in the fragment only condition, words $(M=0.45)$ were recalled better than pictures $[M=0.37 ; F(1,29)=11.18, M S e=0.01]$, whereas in the cued fragment condition, recall of words $(M=0.57)$ and pictures $(M=0.61)$ was not significantly different $[F(1,29)=1.23, M S e=0.02, p=.25]$.

Taken together, the results of the implicit and explicit test conditions indicate that words produced better performance than pictures on the fragment completion task, unless both semantic cues and explicit retrieval instructions were provided. In the latter case, pictures were remembered as well as, but not better than, words. A three-way ANOVA with test orientation, test cue, and study format (pictures vs. words) revealed a three-way interaction $[F(1,116)=3.95, M S \mathrm{e}=0.01]$, verifying these conclusions. These results support the notion that retrieval processes are constrained by the nature of the retrieval cues. On the word-fragment completion task, when fragments are presented alone, retrieval is datadriven such that words are remembered better than pictures. With semantically related cues alone (Experiment 2 and Experiment 3, see below), retrieval is conceptually driven such that pictures are remembered better than words. When the two types of retrieval cues are combined, however, both types of cues can affect retrieval operations such that pictures and words are remembered equally well, but only under explicit retrieval instructions.

Additional analyses of the explicit test conditions revealed that the proportion of false alarms in the fragment only condition $(M=0.11)$ was significantly less than in the cued fragment condition $[M=0.22 ; F(1,58)=6.65$, $M S \mathrm{e}=0.03$ ]. As stated in Experiment 1, the appropriate adjustment for false alarms is not clear. However, an ANOVA on the difference scores (subtracting false alarms) did not change the main conclusions inferred from the above analyses. The main effects of test cue and of study format were not significant $[F(1,58)=2.35$, $M S e=0.06$, and $F(1,58)<1$, respectively]. Adjusting for different baselines equates the performance levels in the two cuing conditions. However, the interaction between test type and study format remains significant $[F(1,58)=7.84, M S e=0.01]$.

Semantic cued recall. When provided with only semantic extralist cues at test, the subjects recalled more pictures $(M=0.51)$ than words $[M=0.25 ; t(1,29)=$ $5.88, S E=0.05]$, replicating the results of Experiment 2 with the weaker associates used here.

Free recall. As was expected, a greater proportion of pictures $(M=0.35)$ was recalled than of words $[M=0.21 ; t(1,29)=5.83, S E=0.02]$.

Confidence ratings. Confidence ratings for pictures, words, and nonstudied items that were completed with the targets in the explicit word-fragment completion groups are presented in Table 4. (Because the rating instructions were incorrectly administered to the implicit test groups, we could not analyze their confidence ratings.)

A 2 (test cue) $\times 3$ (study format) mixed-factor ANOVA revealed that the main effect of study format was significant $[F(2,116)=129.38, M S e=1.09]$, whereas neither the main effect of test type nor the interaction between test type and study format was significant $(F s<1)$. A planned comparison revealed that pictures $(M=5.8)$ received reliably higher ratings than words did $[M=5.3$; $F(1,59)=51.19, M S e=0.12]$.

The proportion of items receiving a rating of 6 (absolutely certain item was presented) is also presented in Table 4, for each condition. The inferential statistics revealed the same pattern of differences that was present in the overall confidence ratings. A $2 \times 3$ ANOVA indicated that only the main effect of study format was significant $[F(2,116)=428.00, M S e=0.03]$. A greater

Table 4

Recognition Confidence for Target Completions on Explicit Word-fragment Completion in Experiment 3

\begin{tabular}{cccc}
\hline & \multicolumn{3}{c}{ Study Format } \\
\cline { 3 - 4 } Test Cue Condition & Pictures & Words & Nonstudied \\
\hline \multicolumn{4}{c}{ Mean Confidence Ratings } \\
Fragment only & 5.8 & 5.3 & 2.8 \\
Cued Fragment & 5.7 & 5.4 & 3.1 \\
& Proportion Rated " 6 ", & \\
Fragment only & .91 & .68 & .07 \\
Cued fragment & .87 & .69 & .10 \\
\hline
\end{tabular}

Note- " 6 " = absolutely certain that the item was presented during the study phase. 
proportion of picture items $(M=0.89)$, as compared to word items $(M=0.69)$, received a confidence rating of $6[F(1,59)=78.49, M S e=0.02]$.

These confidence ratings reveal a dissociation between fragment completion performance and recognition confidence similar to that obtained in Experiment 1 . Although the picture superiority effect was not present on either completion test, it appeared on a recognition confidence test performed on the same items.

\section{GENERAL DISCUSSION}

The main findings from these experiments are as follows: (1) the picture superiority effect is not always obtained on explicit memory tests; (2) the implicit versus explicit nature of the retrieval instructions given to subjects for word-completion tests does not determine whether or not the picture superiority effect will be obtained; (3) the picture superiority effect is obtained on a semantic cued recall test; (4) the advantage of words over pictures on the word-fragment completion test can be eliminated if semantic cues accompany the fragments, and if explicit retrieval instructions are given during the test; however, picture superiority is not reliably reinstated under these conditions; and (5) the word-fragment and wordstem completion tests engage similar retrieval processes, at least with respect to the variables manipulated here.

The most important conclusion to be drawn from these results is that the properties of retrieval cues help determine the relative accessibility of pictures and words. Although words produced more priming than pictures on implicit versions of the word-fragment and word-stem completion tasks, we had suggested that telling subjects to use the fragments and stems as explicit retrieval cues might reinstate the picture superiority effect. We based this hypothesis on the fact that pictures are generally remembered better than words on other memory tests that require explicit retrieval-specifically, on free recall and word-recognition tests. The fact that picture superiority was not obtained on the word-completion tests under explicit recall instructions indicates that the type of processes engaged at retrieval are not entirely under the subjects' (or experimenters') control, and that they depend upon properties of the retrieval cues. Thus, the difference between the cued recall and word completion tests is not simply a function of the retrieval strategies that subjects adopt, but also a function of the cue-determined processes required to perform the tasks.

One type of cue-determined retrieval process is datadriven, or dependent on the match between perceptual processing at study and test. The word fragments and word stems used in Experiments 1 and 3 exhibit this property. These stimuli are perceptually incomplete, or data-limited, and hence they rely on the recovery of perceptual codes for their solution. In terms of Nelson et al.'s (1987) framework, these stimuli probably induced a search of the set of items in memory that share similar orthographic codes (the lexical search set). Prior reading of words facilitated the solution of the fragments and stems because the orthographic information encoded at study was similar to that which served as the basis of test performance. However, prior study of pictures was less helpful, because processing of the surface information needed to resolve the degraded verbal stimuli did not occur. The word-fragment and word-stem completion tests are datadriven, and this property appears to constrain retrieval processes regardless of whether retrieval is implicit or explicit.

An interesting set of data obtained by Blaxton (1985) invites a similar interpretation. She developed a graphemic cued recall test in which subjects were given extralist retrieval cues that were graphemically similar to the studied words (e.g., chopper as a cue for copper), and were told to try to recall studied items that looked like the cue. The subjects recalled more target words with the graphemic cues if they had read the targets during the study phase than if they had generated the targets in response to conceptually related words without actually seeing the target (e.g., penny-c____ Thus, datadriven retrieval effects depended on similarity between the perceptual operations engaged at study and test, and they were not contingent upon an implicit retrieval orientation.

A second type of cue-determined retrieval process is conceptually driven, or dependent upon similarity between semantic processing at study and test. The semantic extralist cues used in Experiments 2 and 3 exhibit this property. Because the cues are meaningfully related to the target items, successful retrieval depends on using conceptual codes to link the cues and targets. In terms of Nelson et al.'s (1987) framework, these cues induced a search of sets of items in memory that share conceptual information with the cue (the semantic search set). Thus, the task is conceptually driven, and processing conceptual information during the study phase increases the success of the conceptually based search. Prior study of pictures was more beneficial than study of words in this task, because pictures engender more of the requisite conceptual processing that underlies semantic cued recall.

When the data-driven and conceptually driven retrieval cues were combined, both affected the retrieval processes engaged. The usual advantage of words over pictures that is obtained with word-fragment cues was eliminated when semantically related cues were presented with the word fragments, but only if explicit retrieval instructions were also given. These results suggest that memory search was both conceptually and perceptually based. However, the fact that these results were obtained only with explicit retrieval instructions, and that picture superiority was not actually reinstated, suggests that data-driven retrieval provides the primary basis for performance on the wordfragment completion task. The importance of the match between the perceptual operations performed at study and test is not easily overridden.

We would like to clarify two points that might be a source of misunderstanding in the theoretical framework 
we have proposed (see Roediger et al., 1989, for further elaboration). First, we do not conceive of data-driven and conceptually driven processes as dichotomous. A task is rarely either conceptually driven or data-driven. Most tasks contain both types of processes, but many tasks can be classified as being predominantly data-driven (e.g., perceptual identification, and word-fragment and wordstem completion), or predominantly conceptually driven (e.g., recognition and recall). We conceive of the dimension as a continuum on which tasks can be ordered according to the relative dominance of their data-driven and conceptually driven components. As was demonstrated in Experiment 3, the dominance of data-driven retrieval can be reduced on the word-fragment completion test by the addition of conceptual information at retrieval.

Second, we would like to emphasize that it is not the physical match between the study and test stimuli per se that is important in determining whether a task is datadriven, but rather the match between the cognitive processes engaged at study and test (Weldon \& Roediger, 1987). On a word recognition test, for example, complete words are presented at both study and test, so their physical features match completely. Therefore, it might seem that word-recognition should be even more data-driven than word-fragment completion, in which the word fragments only partially match the study words. However, although recognition may have a data-driven component, it is primarily conceptually driven, because encoded meaning seems to be the primary basis of recognition decisions (Jacoby, 1983; Jacoby \& Dallas, 1981). For example, pictures are remembered better than words on a wordrecognition test (Madigan, 1983), and levels-of-processing manipulations affect recognition accuracy but have little or no effect on data-driven tasks (e.g., perceptual identification, in Jacoby \& Dallas, 1981). Thus, we argue that retrieval is a function of the similarity between the procedures performed to accomplish the study and test tasks.

From a more general standpoint, our interpretation of the present experiments emphasizes the importance of transfer appropriate processing in retrieval (see Bransford, Franks, Morris, \& Stein, 1979; Morris, Bransford, \& Franks, 1977). An encoding task produces "good" memory only to the extent that the retrieval activities recapitulate acquisition activities. The idea that the match between data-driven and conceptually driven processes is a fundamental basis of transfer (Jacoby, 1983; Roediger \& Blaxton, 1987; Roediger et al., 1989) is one instantiation of the transfer appropriate processing framework. Conceptual processing will be most beneficial on conceptually driven retrieval tasks, but perceptual processing will benefit data-driven tasks. As demonstrated in the experiments reported here, for example, pictures' superior semantic codes are mnemonically advantageous only if the retrieval test provides access to these codes.

The final point we would like to make is that the wordfragment and word-stem completion tasks appear to involve similar retrieval processes, at least with respect to the theoretically interesting variables manipulated in Ex- periment 1 . We base this conclusion on the fact that the two tests behaved similarly under different encoding conditions (pictures vs. words) and retrieval instructions (implicit vs. explicit). Of course, this conclusion is tentative, because it is contingent on accepting the null hypothesis. Obviously, a wider range of variables must be tested in order to address this question adequately.

In summary, the experiments reported here indicate that the properties of retrieval cues determine what types of encoding processes produce good memory. These constraints are inherent in the properties of the retrieval cues, such that data-limited fragments and stems evoke datadriven retrieval processes, whereas semantically related extralist cues evoke conceptually driven retrieval processes. The combination of the two types of cues appears to engage both types of processes under certain conditions.

\section{REFERENCES}

Blaxton, T. A. (1985). Investigating dissociations among memory measures: Suppont for a transfer appropriate processing framework. Unpublished doctoral dissertation, Purdue University, West Lafayette, IN.

Bransford, J. D., Franks, J. J., Morris, C. D., \& Stein, B. S. (1979). Some general constraints on learning and memory research. In $\mathrm{L}$. S. Cermak \& F. I. M. Craik (Eds.), Levels of processing in human memory (pp. 331-354). Hillsdale, NJ: Erlbaum.

Craik, F. I. M., \& LockharT, R. S. (1972). Levels of processing: A framework for memory research. Journal of Verbal Learning \& Verbal Behavior, 11, 671-684.

Craik, F. I. M., Tulving, E. (1975). Depth of processing and the retention of words in episodic memory. Journal of Experimental Psychology: General, 104, 268-294.

Durso, F. T., \& Johnson, M. K. (1980). The effects of orienting tasks on recognition, recall, and modality confusion of pictures and words. Journal of Verbal Learming \& Verbal Behavior, 19, 416-429.

EYSENCK, M. W. (1979). Depth, elaboration, and distinctiveness. In L. S. Cermak \& F. I. M. Craik (Eds.), Levels of processing in human memory. Hillsdale, NJ: Erlbaum.

Graf, P., Mandler, G. (1984). Activation makes words more accessible, but not necessarily more retrievable. Journal of Verbal Learning \& Verbal Behavior, 23, 553-568.

INTRAUB, J., \& NICKLOS, S. (1985). Levels of processing and picture memory: The physical superiority effect. Journal of Experimental Psychology: Learning, Memory, \& Cognition, 11, 284-298.

JACOBY, L. L. (1983). Remembering the data: Analyzing interactive processes in reading. Journal of Verbal Learning \& Verbal Behavior, 22, 485-508.

JACOBY, L. L., DALlas, M. (1981). On the relationship between autobiographical memory and perceptual learning. Journal of Experimental Psychology: General, 111, 306-340.

MAdigan, S. (1983). Picture memory. In J. C. Yuille (Ed.), Imagery, memory and cognition: Essays in honor of Allan Paivio (pp. 65-89). Hillsdale, NJ: Erlbaum.

Morris, C. D., Bransford, J. D., \& FranKs, J. J. (1977). Levels of processing versus transfer appropriate processing. Journal of Verbal Learning \& Verbal Behavior, 16, 519-533.

NeLson, D. L. (1979). Remembering pictures and words: Appearance, significance, and name. In L. S. Cermak \& F. I. M. Craik (Eds.), Levels of processing in human memory (pp. 45-76). Hillsdale, NJ: Erlbaum.

NeLSON, D. L. (in press). Implicitly activated knowledge and memory. In C. Izawa (Ed.), Current issues in cognitive processes: The Tulane Flowerree Symposium on Cognition.

Nelson, D. L., Canas, J. J., Bajo, M. T., \& Keelean, P. D. (1987). Comparing word fragment completion and cued recall with letter cues. 
Journal of Experimental Psychology: Learning. Memory, \& Cognition, 13, 542-552.

Nelson, D. L., Reed, V. S., \& McEvoy, C. L. (1977). Learning to order pictures and words: A model of sensory and semantic encoding. Joumal of Experimental Psychology: Human Learning \& Memory, 3, 485-497.

Paivio, A. (1971). Imagery and verbal processes. New York: Holt, Rinehart \& Winston.

PaIvio, A. (1983). The empirical case for dual coding. In J. C. Yuille (Ed.), Imagery, memory, and cognition: Essays in honor of Allan Paivio (pp. 307-332). Hillsdale, NJ: Erlbaum.

PaIvio, A. (1986). Mental representation: A dual coding approach. New York: Oxford.

Paivio, A., Rogers, T. B., \& Smythe, P. C. (1968). Why are pictures easier to recall than words? Psychonomic Science, 11, 137-138.

PotTer, M. C., \& Faulconer, B. A. (1975). Time to understand pictures and words. Nature, 253, 437-438.

Roediger, H. L., \& BLAXToN, T. A. (1987). Retrieval modes produce dissociations in memory for surface information. In D. S. Gorfein \& R. R. Hoffman (Eds.), The Ebbinghaus Centennial Conference (pp. 349-379). Hillsdale, NJ: Erlbaum.

RoEdiger, H. L., \& Weldon, M. S. (1987). Reversing the picture superiority effect. In M. A. McDaniel \& M. Pressley (Eds.), Imagery and related mnemonic processes: Theories, individual differences, and applications (pp. 151-174). New York: Springer-Verlag.

Roediger, H. L., Weldon, M. S. \& Challis, B. H. (1989). Explaining dissociations between implicit and explicit measures of retention: A processing account. In H. L. Roediger III \& F. I. M. Craik (Eds.), Varieties of memory and consciousness: Essays in Honor of Endel Tulving (pp. 3-41). Hillsdale, NJ: Erlbaum.
SHEPARD, R. N. (1967). Recognition memory for words, sentences, and pictures. Journal of Verbal Learning \& Verbal Behavior, 6, 156-163. SMith, M. C., \& MAGEE, L. E. (1980). Tracing the time course of picture-word processing. Journal of Experimental Psychology: General, 109, 373-392.

SNOdGRASS, J. G., \& VANDERWART, M. (1980). A standardized set of 260 pictures: Norms for name agreement, image agreement, familiarity, and visual complexity. Journal of Experimental Psychology: Human Learning \& Memory, 6, 174-215.

Squire, L. R., Shimamura, A. P., \& Graf, P. (1987). Strength and duration of priming effects in normal subjects and amnesic patients. Neuropsychologia, 25, 195-210.

Tulving, E., Schacter, D. L., \& Stark, H. A. (1982). Priming effects in word-fragment completion are independent of recognition memory. Journal of Experimental Psychology: Learning, Memory, \& Cognition, 8, 336-342.

Warren, C., \& Morton, J. (1982). The effects of priming on picture recognition. British Joumal of Psychology, 73, 117-129.

WELDON, M. S., \& ROEDIGER, H. L. (1987). Altering retrieval demands reverses the picture superiority effect. Memory \& Cognition, 15, 269-280.

WINNICK, W. A., \& Daniel, S. A. (1970). Two kinds of response priming in tachistoscopic recognition. Journal of Experimental Psychology, 84, 74-81.

(Manuscript received September 11, 1987; revision accepted for publication April 1, 1988.) 